\title{
Defining the larval habitat: abiotic and biotic parameters associated with Anopheles farauti productivity
}

Kimberley McLaughlin', Thomas R. Burkot ${ }^{1}$, Jance Oscar², Nigel W. Beebe ${ }^{3,4}$ and Tanya L. Russell ${ }^{1 *}$

\begin{abstract}
Background: In the Solomon Island, the dominant malaria vector, Anopheles farauti, is highly anthropophagic and increasingly exophilic and early biting. While long-lasting insecticide-treated nets remain effective against An. farauti, supplemental vector control strategies will be needed to achieve malaria elimination. Presently, the only World Health Organization recommended supplemental vector control strategy is larval source management (LSM). Effective targeted larval source management requires understanding the associations between abiotic, chemical and biological parameters of larval habitats with the presence or density of vector larvae.

Methods: Potential and actual An. farauti larval habitats were characterized for presence and density of larvae and associated abiotic, chemical and biological parameters.

Results: A third of all sampled potential habitats harboured An. farauti larvae with $80 \%$ of An. farauti positive habitats being in three habitat classifications (swamps/lagoons, transient pools and man-made holes). Large swamps were the most abundant positive habitats surveyed (43\% of all An. farauti positive habitats). Habitats with An. farauti larvae were significantly associated with abiotic ( $\mathrm{pH}$, nitrate, ammonia and phosphate concentrations and elevated temperature) and biotic (predators) parameters.

Conclusion: Large swamps and lagoons are the largest and most abundant An. farauti habitats in the Solomon Islands. Positive habitats were more frequently associated with the presence of predators (vertebrates and invertebrates) and higher water temperatures. Cohabitation with predators is indicative of a complex habitat ecosystem and raises questions about the potential of biological control as an effective control strategy. Increased presence of An. farauti with higher water temperature suggests a potential explanation for the coastal distribution of this species which is not found inland at elevated altitudes where temperatures would be cooler.
\end{abstract}

Keywords: Anopheles farauti, Anopheles hinesorum, Anopheles lungae, Malaria, Receptivity, Elimination, Density, Wing length, Solomon Islands

\section{Background}

The geographic distribution of malaria vector species is an important component defining the receptivity of an area for malaria and for stratifying interventions for their control [1]. The World Health Organization (WHO) Global

\footnotetext{
*Correspondence: tanya.russell@jcu.edu.au

1 James Cook University, Australian Institute of Tropical Health

and Medicine, Cairns, QLD 4870, Australia

Full list of author information is available at the end of the article
}

Technical Strategy for Malaria Control and Elimination recommends universal access to vector control with either long-lasting insecticide-treated nets (LLINs) or indoor residual spraying (IRS) to all people at-risk of malaria [2]. However, the recent stabilization in the number of global malaria cases suggests that novel interventions tools will be required to further reduce malaria transmission [3]. At the present time, the only WHO recommended strategy to control vectors outdoors is larval source management (LSM) in areas with seasonal transmission or where the 
larval habitats are few in number, fixed in location and easily accessible (including urban areas) [2, 4]. Understanding larval habitats is necessary for implementing effective LSM.

Mirroring the global pattern, the Solomon Islands achieved significant reductions in malaria cases following universal distribution of LLINs, but the number of cases has increased since 2015 to a prevalence of 80 cases/1000 population in 2017 (Solomon Island Annual Malaria Programme Report, 2017). Six members of the Anopheles punctulatus group are found in the Solomon Islands [5]. Anopheles farauti is the dominant malaria vector [6]. Anopheles punctulatus, once found across the Solomon Islands, is now confined to Guadalcanal and Malaita Provinces as a consequence of the IRS campaigns with DDT in the 1970s [7]. Anopheles koliensis, a major vector in Papua New Guinea [8], may have been eliminated from the Solomon Islands as a consequence of IRS with DDT [9], as this species has not been found in in the Solomon Islands since 1987 [7]. While Anopheles hinesorum is a malaria vector in Papua New Guinea [10], only a single sporozoite positive individual was found in Western Province, Solomon Islands and this species is unlikely to maintain malaria transmission due to its predominantly zoophagic biting habit in the Solomon Islands [6]. The vector status of Anopheles rennellensis is unknown, and Anopheles irenicus has not been collected using human landing catches and so is not regarded as a malaria vector [8]. Hence, malaria vector control in the Solomon Islands focuses on An. farauti.

Recent surveys in Central and Western Provinces identified larval habitats of An. farauti, An. hinesorum, Anopheles lungae, Anopheles solomonis and Anopheles nataliae, the latter three species belonging to the An. lungae complex [11, 12]. Larvae of An. lungae, An. solomonis and $A n$. nataliae were most frequently found in riverine habitats, with An. lungae also found in swamps and lagoons in Central and Western Provinces [11]. While An. farauti and An. hinesorum were found in a range of habitat types, the most frequently utilized were coastal lagoons and swamps, hypothesized to be responsible for producing most adults [11], as the highest populations of An. farauti are found in villages near large brackish water lagoons and freshwater swamps $[6,13,14]$.

Characterization of An. farauti larval habitats to date has been limited. Anopheles farauti has only been found predominantly near the coast [10]. On Guadalcanal, An. farauti larvae are associated with emergent plants and filamentous algae with highest larval densities found closest to the mouths of saline lagoons [15]. This study aimed to determine abiotic and biotic parameters associated with prevalence and productivity of anophelines in the Western and Central Provinces of the Solomon Islands. Understanding the characteristics associated with $A n$. farauti larvae may enable rapid identification of productive habitats for targeted larval control.

\section{Methods}

\section{Study period and sites}

Larval surveys were conducted during January and August 2016 near villages in Western Province (Jack Harbour, Saeragi, Kinamara, and New Mala; $-8.0^{\circ} \mathrm{S}, 157.0^{\circ} \mathrm{E}$ ) and Central Province (Haleta; - 9 ${ }^{\circ} 5^{\prime} 56^{\prime \prime}$ S, $160^{\circ} 6^{\prime} 56^{\prime \prime}$ E) of the Solomon Island (Fig. 1) [6]. The villages are on volcanic, rain-forested mountainous islands. The climate of the region is hot and wet with annual rainfall of $3725 \mathrm{~mm}$ and

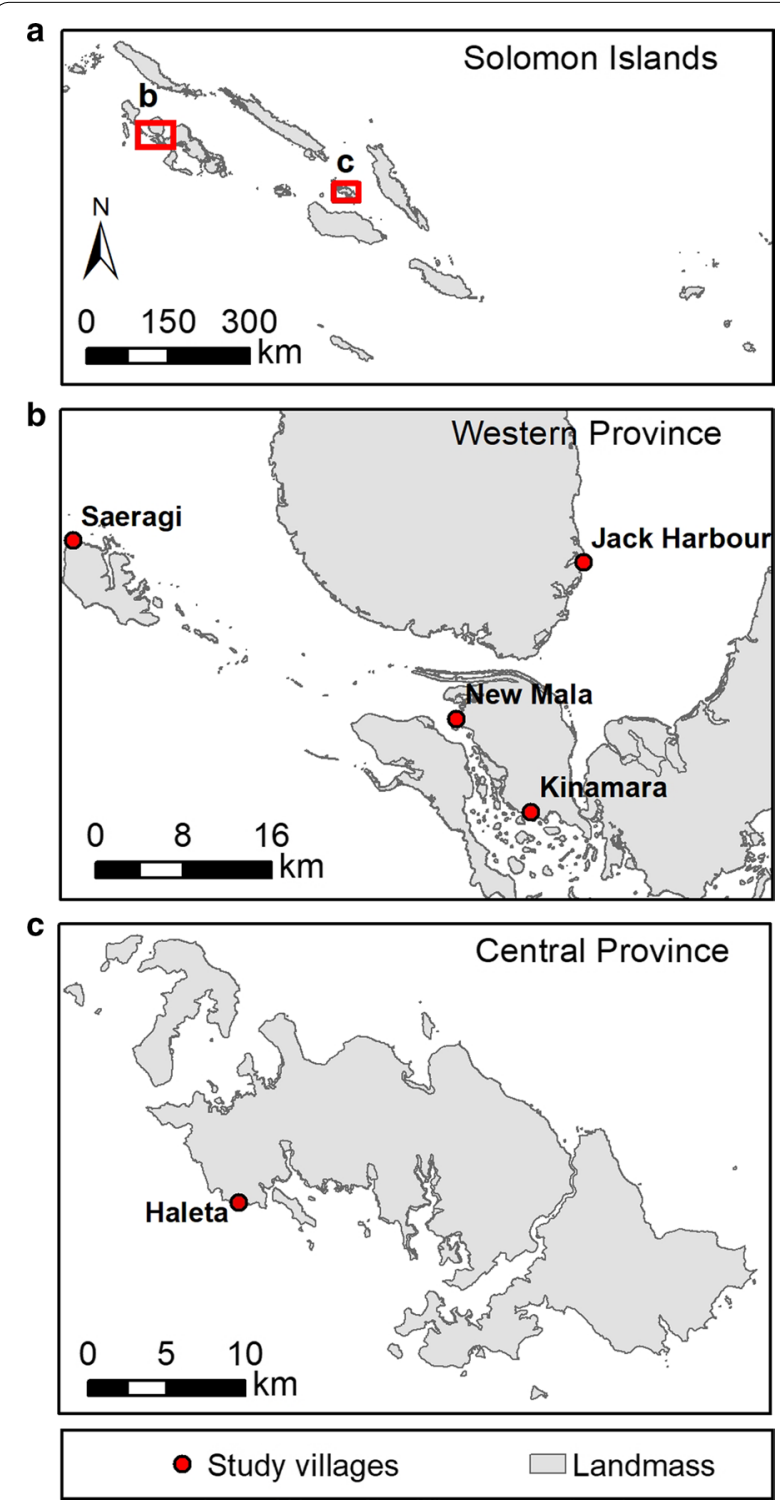

Fig. 1 Map of (a) the Solomon Islands showing locations of (b) the 4 study villages in Western Province $\left(8^{\circ} 0^{\prime} \mathrm{S}, 157^{\circ} 0^{\prime} \mathrm{E}\right)$ and (c) Haleta village in Central Province $\left(9^{\circ} 0^{\prime} \mathrm{S}, 159^{\circ} 45^{\prime} \mathrm{E}\right)$ 
$2837 \mathrm{~mm}$ for New Georgia Island, Western Province and Central Province, respectively, from 1999 to 2010 (Solomon Islands Meteorology Department for Munda Airport, Western Province, and Henderson Airport for Central Province, unpublished data). The mean daily minimum and maximum temperatures of both provinces were $24{ }^{\circ} \mathrm{C}$ and $30^{\circ} \mathrm{C}$, respectively, with an overall mean of $26^{\circ} \mathrm{C}$.

\section{Habitat characterization}

The study villages and surrounding areas were extensively searched for potential larval habitats. Potential larval habitats were sampled for mosquito immature stages using $250 \mathrm{ml}$ dippers, with 10 samples (dips) taken at each station. Habitats with water but without larvae present were recorded as negative habitats, areas with water and larvae were recorded as "positive habitats" and areas previously with water but now dry recorded as potential habitats. Habitats with perimeters larger than $10 \mathrm{~m}$ were sampled at multiple stations between 5 and $10 \mathrm{~m}$ apart. The geoposition of sampling stations were recorded (Juno Trimble 3D). Larvae captured were counted by instars and stored in $70 \%$ ethanol for subsequent identification by PCR using the internal transcribed spacer region II of ribosomal DNA (ITS2) [16].

Environmental parameters included abiotic and biotic categories that were further defined by sub-categories (classifications) (an additional table provides further detail, see Additional file 1: Table S1). Habitat classifications were transient pools, lagoon or swamp, drains, man-made holes, water storage containers, riverine habitats, ponds, and rock pools.

Abiotic characteristics included the substrate (habitat floor), water depth, bank slope, size (as defined by perimeter circumference), light intensity, debris present, chemical concentrations and temperature. Substrate classifications were rock, gravel, sand and silt [17]. Water depth was measured approximately $30 \mathrm{~cm}$ from the habitat edge (or centrally for small habitats) and analysed in $5 \mathrm{~cm}$ increments. Bank slope was recorded as gentle $\left(0-19^{\circ}\right.$ angle), moderate (20-49 angle) and steep (50-90 angle). Habitat perimeters were classified as small $(<10 \mathrm{~m})$, medium $(10-100 \mathrm{~m})$, and large $(>100 \mathrm{~m})$. Light intensity was classified by the amount of sunlight illuminating the habitat (i.e., none, partial sun, or full sun). Debris classes of natural or man-made materials floating or immersed in the habitat were none, dead plant materials, man-made materials, biological surface film (scum), and floating pumice. Temperature, salinity and $\mathrm{pH}$ were quantified with a Cyberscan series $600 \mathrm{PCD}$ 650 meter. Chemicals measured were sodium chloride (salinity), nitrate $(\mathrm{mg} / \mathrm{L})$, ammonia $(\mathrm{mg} / \mathrm{L})$ and phosphate $(\mathrm{mg} / \mathrm{L})$ Nitrate, ammonia and phosphate concentrations were measured semi-quantitatively using Quantofix test strips (Macherey-Nagel; Duren, Germany).
Biotic parameters were classified by canopy (vegetation above habitats), vegetation (living within the aquatic habitat), and predators. Canopy classifications were none, shrub, and tree. Vegetation classifications were none, trees, bushes, algae, floating vegetation, and emergent. Predator classifications were fish, tadpoles, dragonfly nymphs, water striders, and others.

\section{Statistical analysis}

The influence of environmental parameters on the presence and density of anopheline larvae was analysed using Generalized Linear Mixed Models (GLMM) with a unique identifier for habitat as a random variable to account for repeated sampling. The data was analysed with two different distributions: (1) binary data (presence and absence) was fitted to a binomial distribution, and (2) count data was fitted to a negative binomial distribution as count data was not normally distributed. Larval collection stations with zero larvae counts were excluded from density analyses. All analyses were conducted using the $R$ package V3.6.0 [18].

\section{Results}

\section{Larval distribution}

Anopheline larvae were sampled from 67 larval habitats, 41 in Western Province (Jack Harbour: $\mathrm{n}=13$; Kinamara: $\mathrm{n}=6$; New Mala: $\mathrm{n}=10$; and Saeragi: $\mathrm{n}=12$ ) and 26 in Haleta village in Central Province. The number of sample stations per habitat ranged from 1 to 24 , depending on habitat size. Overall, 324 anopheline larvae were identified to species by PCR. Anopheles farauti was the most abundant and widespread species, being found in all surveyed villages. Anopheles hinesorum larvae were only collected in Kinamara village, where this species made up $79 \%$ of identified specimens.

Anopheles farauti immatures were found in a wide range of habitat classifications: coastal lagoons and swamps, transient pools, man-hade holes, riverine habitats, drains and ponds. The most commonly occupied habitats were lagoons and swamps, transient pools and man-made holes (Table 1).

\section{Larval prevalence by abiotic and biotic parameters}

Associations of abiotic and biotic parameters with larvae presence are shown in Figs. 2, 3 and 4. Six larval habitat parameters were significantly and positively associated with $A n$. farauti presence (Table 2): predators $(P=0.018)$, temperature $(P<0.001), \mathrm{pH}(P=0.008)$, nitrate $(P=0.005)$, ammonia $(P=0.022)$ and phosphate $(P=0.003)$. The mean temperature of larval positive habitats $\left(29.8^{\circ} \mathrm{C}\right)$ was $2.3^{\circ} \mathrm{C}$ greater than the average temperature of negative habitats. Positive larval habitats had a mean $\mathrm{pH}$ of 8.5 , whereas negative sites had a mean $\mathrm{pH}$ of 8.1. Anopheles farauti larvae were found significantly more frequently in habitats 
Table 1 Larval habitats of An. farauti s.s. in Central and Western Provinces, Solomon Islands

\begin{tabular}{lccc}
\hline Habitat classification & $\begin{array}{c}\text { Number } \\
\text { habitats }\end{array}$ & $\begin{array}{l}\text { Number } \\
\text { positive }\end{array}$ & $\begin{array}{l}\text { Habitat } \\
\text { classification } \\
\text { positive (\%) }\end{array}$ \\
\hline Lagoon or swamp & 42 & 12 & 29 \\
Transient pools & 34 & 8 & 24 \\
Man-made holes & 20 & 8 & 40 \\
Rivers & 6 & 4 & 67 \\
Drains & 2 & 2 & 100 \\
Pond & 1 & 1 & 100 \\
Water storage containers & 2 & 0 & 0 \\
Grand total & 107 & 35 & 33 \\
\hline
\end{tabular}

with concentrations of nitrate $>250 \mathrm{mg} / \mathrm{L}$, at ammonia concentrations of $6 \mathrm{mg} / \mathrm{L}$ or phosphate concentrations of $100 \mathrm{mg} / \mathrm{L}$. Parameters not associated with larvae presence were substrate, water depth, habitat size, bank slope, canopy type, sunlight, vegetation, debris and salinity.

\section{Larval density and abiotic, chemical and biological parameters}

Associations of abiotic and biotic parameters with larval density (the total number of larvae per 10 dips) are summarized in additional figures (see Additional file 2: Figures S1, S2, S3). Temperature was significantly and positively associated with An. farauti density $(P=0.003)$ (Table 2).
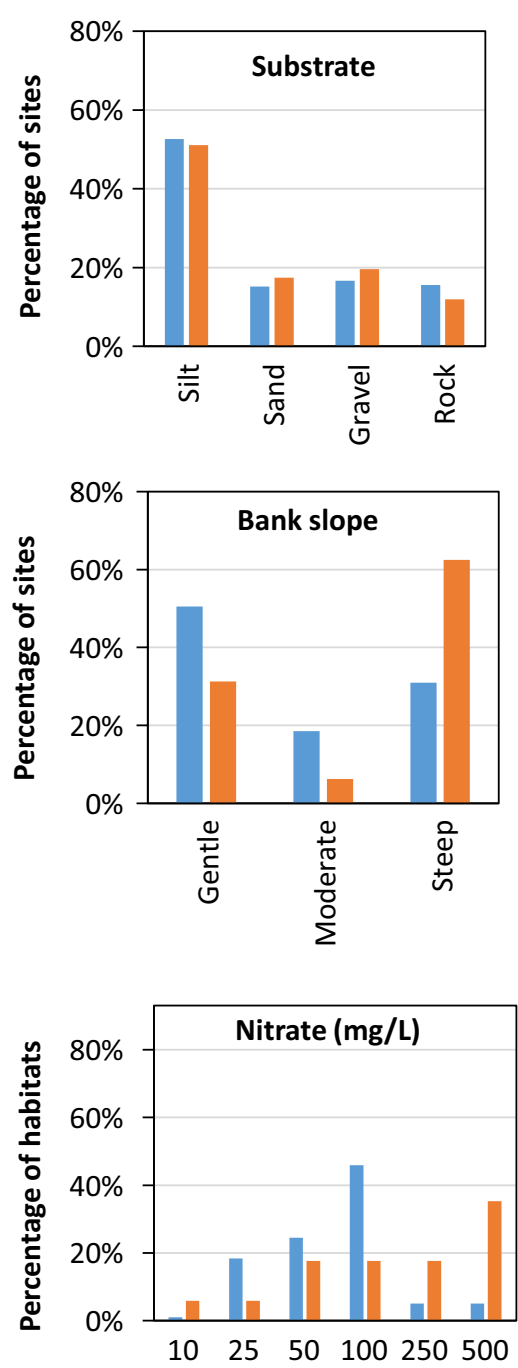
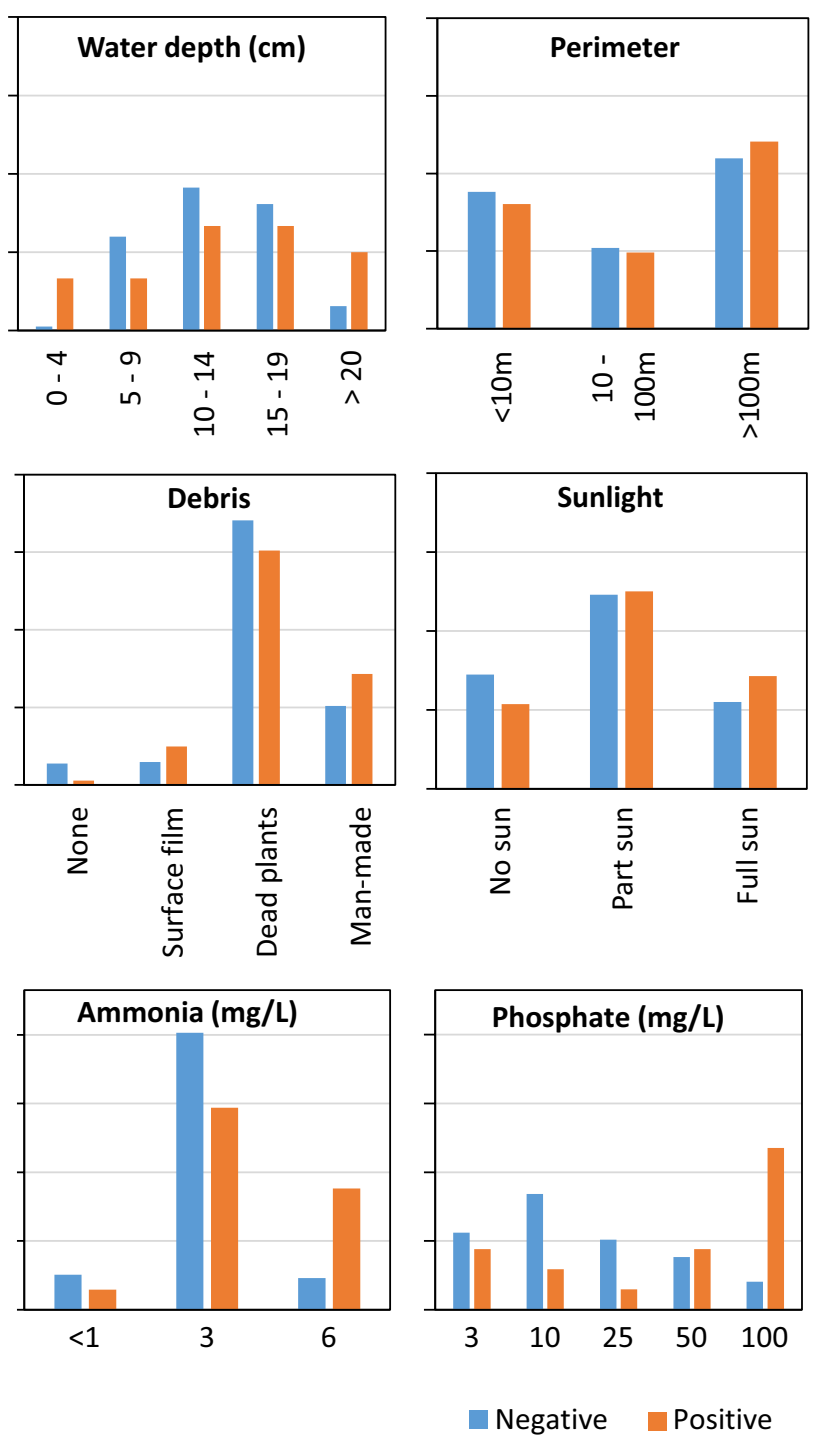

Fig. 2 Associations of abiotic parameters analysed categorically against the presence of An. farauti larvae in aquatic habitats 

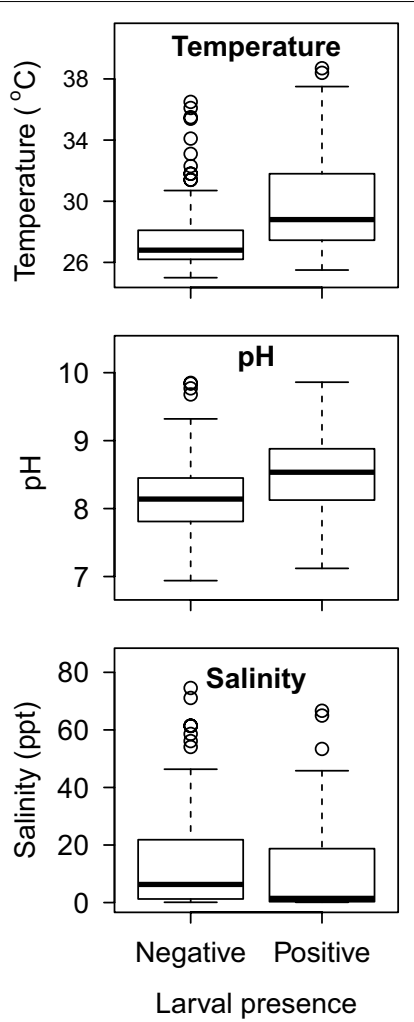

Fig. 3 Associations between abiotic parameters analysed continuously against the presence of An. farauti larvae in larval habitats

\section{Discussion}

Larval habitats in the Solomon Islands were examined for associations between abiotic and biotic parameters and the prevalence or density of An. farauti larvae. This research was conducted in response to previous studies that had highlighted that the distribution of An. farauti larvae was not uniform $[11,15]$. During the current survey, only a third of potential habitats contained An. farauti during two surveys, and markers that might be used for targeting habitats with immature stages were sought. Here, the most commonly occupied habitats were lagoons and swamps, transient pools and man-made holes, which was similar to previous surveys in the region [11].

Quantitative larval surveys are fraught with challenges, particularly in large habitats as larvae are not uniformly distributed and thus requires sampling multiple sites within a habitat to establish with some certainty if and where larvae are present, particularly for anophelines which are frequently found in low densities. Distinguishing high from low productivity of large habitats is challenging as the emergence rates of adults will be a function of mature larval density, rate of development (a function of multiple factors including nutrient sources and temperature), the size of the habitat and the moderating impact of predators located in the habitat. A final challenge is that larval counts in a dipper cannot be related to either density of larvae per habitat area or numbers of adults $[19,20]$.

Hence, analyses of environmental habitat parameters for productivity are better served by looking for associations with the presence of larvae rather than the density of larvae. Significant associations of An. farauti larval presence and nitrate, ammonia and phosphate concentrations, $\mathrm{pH}$ and temperature were found. It is generally accepted that the development of anopheline larvae is strongly influenced by the abiotic and biotic factors of the aquatic habitats. For example, Anopheles gambiae larval densities depend on variables such as nitrogen, temperature, $\mathrm{pH}$, dissolved oxygen and salinity [21-25]. Here similar parameters also influence the presence of $A n$. farauti larvae. This supports the
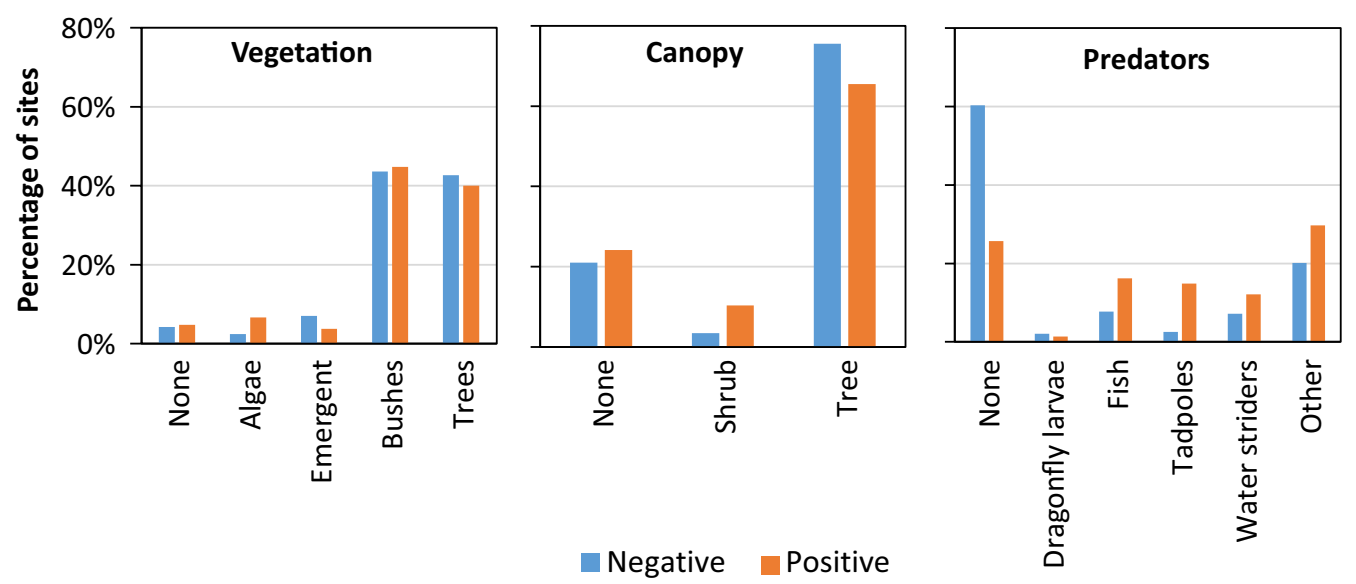

Fig. 4 Associations between biotic parameters and the presence of An. farauti larvae in aquatic habitats 
Table 2 Association of abiotic and biotic parameters with the presence and density of An. farauti larvae in Central and Western Provinces, Solomon Islands

\begin{tabular}{|c|c|c|c|c|c|c|}
\hline \multirow[t]{2}{*}{ Parameter } & \multicolumn{3}{|c|}{ Binary (presence/absence) model } & \multicolumn{3}{|c|}{ Negative binomial (density) model } \\
\hline & $\beta$ & $S E$ & $P$ value & $\beta$ & $S E$ & $P$ value \\
\hline Substrate & -0.016 & 0.1388 & 0.907 & -0.038 & 0.0731 & 0.600 \\
\hline Water depth & 0.166 & 0.2015 & 0.408 & 0.049 & 0.0379 & 0.196 \\
\hline Perimeter & 0.154 & 0.2690 & 0.564 & -0.260 & 0.1966 & 0.185 \\
\hline Bank slope & 2.149 & 1.2800 & $0.093^{\circ}$ & 0.093 & 0.3071 & 0.760 \\
\hline Canopy type & -0.058 & 0.2364 & 0.805 & -0.112 & 0.1533 & 0.466 \\
\hline Sunlight & 0.137 & 0.2144 & 0.522 & 0.159 & 0.1841 & 0.385 \\
\hline Vegetation & -0.053 & 0.0991 & 0.586 & -0.044 & 0.0551 & 0.416 \\
\hline Debris & -0.200 & 0.2612 & 0.443 & 0.009 & 0.1502 & 0.950 \\
\hline Predators & 0.365 & 0.1551 & $0.018^{*}$ & 0.001 & 0.0897 & 0.985 \\
\hline Temperature & 0.293 & 0.0739 & $<0.001^{*}$ & 0.116 & 0.0398 & $0.003^{*}$ \\
\hline $\mathrm{pH}$ & 0.863 & 0.3242 & $0.008^{*}$ & 0.457 & 0.2593 & $0.077^{\circ}$ \\
\hline Salinity & 0.061 & 0.1799 & 0.733 & 0.092 & 0.1592 & 0.563 \\
\hline Nitrate & 0.006 & 0.0023 & $0.005^{*}$ & -0.154 & 0.3041 & 0.611 \\
\hline Ammonia & 0.752 & 0.3294 & $0.022^{*}$ & 0.221 & 0.1428 & 0.120 \\
\hline Phosphate & 0.028 & 0.0095 & $0.003^{*}$ & -0.418 & 0.2770 & 0.131 \\
\hline
\end{tabular}

Data were compared with GLMMs with the habitat identifier as a random variable to account for repeated sampling. The data was analysed with two different distributions: (1) binary data (presence or absence) was fitted to a binomial distribution, and (2) count data were fitted to a negative binomial distribution. For the density analysis, all sampling sites with zero counts of larvae were excluded

literature demonstrating the association of $A n$. farauti with salinity $[15,26,27]$. The increased association of habitats with elevated temperatures with An. farauti presence is consistent with the distribution records for this species and may be a factor in explaining its predominantly coastal distribution.

Interestingly, An. farauti larvae were significantly more often found associated with the presence of predators suggesting co-habitation of more complex aquatic ecosystems (and raising concerns about the potential impact of biological control). Similar observations were made for Anopheles albimanus in the Pacific region of Colombia, where larval density was highest in sites with abundant and varied aquatic fauna, including different predators [28]. Similarly, there are examples where An. gambiae are more abundant in habitats containing tadpoles [24]. This provides further evidence to indicate that the relationship between the biotic and abiotic parameters and oviposition choice and larval development is complex.

\section{Conclusions}

Associations between abiotic and biotic parameters and larval presence suggests that assaying habitats for these parameters might be a more efficient means to select targets for larval source management compared to traditional larval surveys. Overall the findings in this study support the idea that larval control is a feasible option for vector control that could complement the wide-scale use of LLINs and IRS in the region. Especially, as the primary larval habitat of An. farauti in the Solomon Islands were "few (in number), fixed (permanent swamps) and findable (located close to villages)" [29]. However, the entomological and epidemiological evidence to support the implementation of LSM is required.

\section{Supplementary information}

Supplementary information accompanies this paper at https://doi. org/10.1186/s12936-019-3049-7.

Additional file 1: Table S1. The definitions and classifications for environmental parameters of larval habitats.

Additional file 2: Figure S1. Comparison of the influence of abiotic parameters that were analysed categorically on the density of An. farauti larvae in aquatic habitats. Figure S2. Comparison of the influence of abiotic parameters that were analysed continuously on the density of $A n$. farauti larvae in aquatic habitats. Figure S3. Comparison of the influence of biotic parameters on the density of An. farauti larvae in aquatic habitats.

\section{Abbreviations}

IRS: indoor residual spraying; LLIN: long-lasting insecticide treated nets; LSM: larval source management; WHO: World Health Organization.

\section{Acknowledgements}

The authors would like to thank the communities in Western and Central Province of the Solomon Islands for their cooperation and hospitality. The support of Albino Bobogare, Director of the National Vector Borne Disease Control Program, Solomon Islands is gratefully acknowledged. 


\section{Authors' contributions}

Study design, manuscript preparation and data analysis: KML, TLR, TRB. Data collection: KMcL, OJ, TRB. Laboratory processing: KML, NB. All authors read and approved the final manuscript.

\section{Funding}

This work was supported by Grant No. 45114 from the Bill and Melinda Gates Foundation to the Malaria Transmission Consortium and the National Institute of Allergy and Infectious Diseases of the National Institutes of Health for the International Centers of Excellence in Malaria Research in the Southwest Pacific (subaward U19AI08986 to James Cook University). KMcL was supported by a James Cook University Postgraduate Research Scholarship.

\section{Availability of data and materials}

The datasets supporting this article are available from the JCU Tropical Data Hub repository: http://dx.doi.org/10.25903/5d3fd8a0a957c.

\section{Ethical approval and consent to participate}

Not applicable.

\section{Consent for publication}

Not applicable.

\section{Competing interests}

The authors declare that they have no competing interests.

\section{Author details}

1 James Cook University, Australian Institute of Tropical Health and Medicine, Cairns, QLD 4870, Australia. ${ }^{2}$ Western Province Malaria Control, Gizo, Western Province, Solomon Islands. ${ }^{3}$ School of Biological Sciences, University of Queensland, St. Lucia, QLD 4068, Australia. ${ }^{4}$ CSIRO, Dutton Park, Brisbane, QLD 4001, Australia.

Received: 9 August 2019 Accepted: 2 December 2019

Published online: 11 December 2019

\section{References}

1. WHO. Disease surveillance for malaria elimination: an operational manual. Geneva: World Health Organization; 2012.

2. WHO. Global technical strategy for malaria 2016-2030. Geneva: World Health Organization; 2015.

3. World Health Organization. World malaria report. Geneva: World Health Organization; 2018.

4. Tusting LS, Thwing J, Sinclair D, Fillinger U, Gimnig J, Bonner KE, Bottomley C, Lindsay SW. Mosquito larval source management for controlling malaria. Cochrane Database Syst Rev. 2013. https://doi. org/10.1002/14651858.CD008923.pub2.

5. Beebe N, Russell T, Burkot T, Lobo N, Cooper R. The systematics and bionomics of malaria vectors in the southwest Pacific. In: Manguin S, ed Anopheles mosquitoes - new insights into malaria vectors. InTechOpen Publ. 2013:357-94.

6. Burkot TR, Bugoro H, Apairamo A, Cooper RD, Echeverry DF, Odabasi D, et al. Spatial-temporal heterogeneity in malaria receptivity is best estimated by vector biting rates in areas nearing elimination. Parasit Vectors. 2018;11:606.

7. Samarawickrema WA, Parkinson AD, Kere N. Seasonal abundance and biting behaviour of Anopheles punctulatus and An.koliensis in Malaita Province, Solomon Islands, and a trial of permethrin impregnated bednets against malaria transmission. Med Vet Entomol. 1992;6:371-8.

8. Beebe NW, Russell T, Burkot TR, Cooper RD. Anopheles punctulatus group: evolution, distribution, and control. Annu Rev Entomol. 2015;60:335-50.

9. Taylor B. Observations on malaria vectors of the Anopheles punctulatus complex in the British Solomon Islands Protectorate. J Med Entomol. 1975:11:677-87.
10. Cooper RD, Waterson DGE, Frances SP, Beebe NW, Sweeney AW. Speciation and distribution of the members of the Anopheles punctulatus (Diptera: Culicidae) group in Papua New Guinea. J Med Entomol. 2002;39:16-27.

11. Russell TL, Burkot TR, Bugoro H, Apairamo A, Beebe NW, Chow WK, et al. Larval habitats of the Anopheles farauti and Anopheles lungae complexes in the Solomon Islands. Malar J. 2016:15:164.

12. Taylor B, Maffi M. A review of the mosquito fauna of the Solomon Islands (Diptera: Culicidae). Pac Insects. 1978:19:165-248.

13. Hii JL, Kanai L, Foligela A, Kan SK, Burkot TR, Wirtz RA. Impact of permethrin-impregnated mosquito nets compared with DDT house spraying against malaria transmission by Anopheles farauti and An. punctulatus in the Solomon Islands. Med Vet Entomol. 1993;7:333-8.

14. Hii JL, Birley MH, Kanai L, Foligeli A, Wagner J. Comparative effects of permethrin-impregnated bednets and DDT house spraying on survival rates and oviposition interval of Anopheles farauti No. 1 (Diptera: Culicidae) in Solomon Islands. Ann Trop Med Parasitol. 1995;89:521-9.

15. Bugoro H, Hii J, Russell T, Cooper R, Chan B, Iro'ofa C, et al. Influence of environmental factors on the abundance of Anopheles farauti larvae in large brackish water streams in Northern Guadalcanal, Solomon Islands. Malar J. 2011;10:262.

16. Beebe NW, Saul A. Discrimination of all members of the Anopheles punctulatus complex by polymerase chain reaction-restriction fragment length polymorphism analysis. Am J Trop Med Hyg. 1995;53:478-81.

17. ASTM D6913/D6913M-17. Standard test methods for particle-size distribution (gradation) of soils using sieve analysis. West Conshohocken: ASTM International, 2017.

18. R: a language and environment for statistical computing [program]. 3.6.0 version. Vienna: R Foundation for Statistical Computing, 2019.

19. Service MW. Studies on sampling larval populations of the Anopheles gambiae complex. Bull World Health Organ. 1971:45:169-80.

20. Knight KL. Quantitative methods for mosquito larval surveys. J Med Entomol. 1964:1:109-15.

21. Lyimo E, Takken W, Koella JC. Effect of rearing temperature and larval density on larval survival, age at pupation and adult body size of Anopheles gambiae. Entomol Exp Appl. 1992;63:265-71.

22. Mwangangi JM, Muturi EJ, Shililu J, Muriu S, Jacob B, Kabiru EW, et al. Environmental covariates of Anopheles arabiensis in a rice agroecosystem in Mwea, Central Kenya. J Am Mosq Control Assoc. 2007;23:371-7.

23. Awolola TS, Oduola AO, Obansa JB, Chukwurar NJ, Unyimadu JP. Anopheles gambiae ss breeding in polluted water bodies in urban Lagos, southwestern Nigeria. J Vector Borne Dis. 2007:44(4):241.

24. Ndenga BA, Simbauni JA, Mbugi JP, Githeko AK. Physical, chemical and biological characteristics in habitats of high and low presence of anopheline larvae in western Kenya highlands. PLoS ONE. 2012;7:e47975.

25. Mala AO, Irungu LW. Factors influencing differential larval habitat productivity of Anopheles gambiae complex mosquitoes in a western Kenyan village. J Vector Borne Dis. 2011;48:52-7.

26. Bell D, Bryan J, Cameron A, Foley D, Pholsyna K. Salinity tolerance of Anopheles farauti Laveran sensu stricto. P N G Med J. 1999;42:5-9.

27. Sweeney AW. Larval salinity tolerances of the sibling species of Anopheles farauti. J Am Mosq Control Assoc. 1987;8:589-92.

28. Martin GG, Suárez MF, Astaeza R. An ecological survey of Anopheles albimanus larval habitats in Colombia. J Vector Ecol. 1996;21:122-31.

29. WHO. Interim position statement-the role of larviciding for malaria control in sub-Saharan Africa. Geneva: World Health Organization, 2012.

\section{Publisher's Note}

Springer Nature remains neutral with regard to jurisdictional claims in published maps and institutional affiliations. 